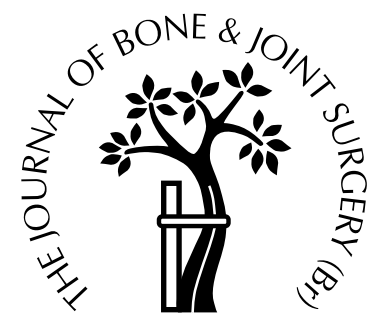

\title{
Incidence and natural history of deep-vein thrombosis after total knee arthroplasty
}

\author{
A PROSPECTIVE, RANDOMISED STUDY \\ Young-Hoo Kim, J.-S. Kim \\ From the Joint Replacement Centre of Korea affiliated with \\ Hae Min General Hospital, Seoul, Korea
}

W

e have evaluated prospectively the incidence and location of deep-vein thrombosis (DVT), the risk factors for pulmonary embolism, and the natural history of thrombosis after total knee replacement (TKR) in patients who did not receive prophylactic or therapeutic treatment for DVT.

We studied 227 patients who underwent primary TKR; 116 had one-stage bilateral and 111 unilateral procedures. Coagulation assays, the full blood count and blood typing tests for the serum chemical profile were undertaken in all patients on three separate occasions. Bilateral simultaneous or unilateral venograms were carried out at six or seven days after operation. Perfusion lung scanning was undertaken before and at seven or eight days after operation. Bilateral simultaneous or unilateral venograms were repeated six months after operation in all patients who had thrombi.

In the 116 patients with a bilateral replacement, 97 of 232 venograms $(\mathbf{4 1 . 8 \%})$ were positive for fresh thrombi while there were 46 positive venograms $(41.4 \%)$ in the 111 patients with a unilateral replacement $(p=1.000)$. Of the 116 venograms in knees with a cemented replacement, $45(38.8 \%)$ were positive for thrombi while 52 of the 116 venograms $\mathbf{4 4 . 8 \% )}$ were positive in those with a cementless replacement $(p=0.675)$. Further venograms at six months after operation in all 143 limbs which had thrombi showed that all had completely resolved regardless of the size or location. No pulmonary embolism occurred as shown by negative perfusion lung scans and the absence of symptoms.

Although the current prevailing opinion is that patients with thrombosis in the proximal veins should receive anticoagulant treatment, our study has shown

Young-Hoo Kim, MD, President and Director

J.-S. Kim, MD, Orthopaedic Surgeon

The Joint Replacement Centre of Korea affiliated with Hae Min General Hospital, 627-3 Jayang 1-Dong, Kwang Jin-Gu, Seoul (143-191), Korea.

Correspondence should be sent to Dr Young-Hoo Kim.

(C)2002 British Editorial Society of Bone and Joint Surgery 0301-620X/02/412330\$2.00 that all thrombi regardless of their size or location resolved without causing pulmonary embolism.

J Bone Joint Surg [Br] 2002;84-B:566-70.

Received 3 April 2001; Accepted after revision 20 July 2001

Thromboembolic disease is a potentially serious complication of total knee replacement (TKR). Routine postoperative venography has shown an incidence of isolated calf thrombi of between $23.8 \%$ and $60 \%$ and of proximal thrombi berween $3 \%$ and $20 \% .^{1-14}$ Since pulmonary embolism is one of the most feared complications, the recognition of deep-vein thrombosis (DVT) in the lower limb has been considered to be an absolute indication for anticoagulation. ${ }^{4,6,15-17}$ Not all deep-venous thrombi, however, give rise to pulmonary emboli. ${ }^{18}$

If some forms of DVT have a lower risk of embolisation than others, ${ }^{19,20}$ their recognition and separation could provide a guideline for selecting patients who are to be exposed to the risks of anticoagulation. ${ }^{21}$ Our prospective study evaluated the incidence and location of DVT, the risk factors for pulmonary embolism and the natural history of thrombosis after TKR in patients who have not received prophylactic or therapeutic treatment for DVT.

\section{Patients and Methods}

Between June 1998 and December 1999, 227 patients had primary TKR using an Omnifit prosthesis (Stryker, Allendale, New Jersey). All were approved by the Internal Review Board of our institution and all gave informed consent for inclusion in the study. Of these, 116 had a onestage bilateral and 111 unilateral TKR. There were 36 men and 80 women with a mean age of 66.7 years (51 to 77) in the bilateral group and 28 men and 83 women with a mean age of 63 years (32 to 73) in the unilateral group. Symptoms of DVT were present in 15 patients (12.9\%) with bilateral and in ten $(9 \%)$ with unilateral TKR. No patient had symptomatic pulmonary embolism.

In the 116 patients with bilateral TKR a cemented prosthesis was introduced on one side and an uncemented prosthesis on the other. Randomisation between cemented and cementless prostheses in the bilateral group was determined from a sequential pool maintained by the statis- 
ticians, based on a table of randomised numbers. All randomisation was done in the operating room just before surgery. There was an equal chance of the cemented or the cementless procedure being carried out first in a bilateral procedure. All 111 unilateral TKRs were cemented. All patients were requested to discontinue aspirin or aspirincontaining compounds and other antiplatelet medication two weeks before admission.

In the bilateral group, 104 patients $(89.6 \%)$ had osteoarthritis, seven (6.1\%) rheumatoid arthritis and five (4.3\%) osteonecrosis of the medial femoral condyle. In the unilateral group, there were 103 patients (92.8\%) with osteoarthritis, six (5.4\%) with rheumatoid arthritis and two (1.8\%) with osteonecrosis of the medial femoral condyle. All patients were followed for at least one year after TKR.

During the operation, a thigh tourniquet was applied, but it was not inflated until just before the insertion of the components. The tourniquet pressure was $150 \mathrm{mmHg}$ above the systolic blood pressure. It was deflated immediately after insertion of the components. The tourniquet technique was the same whether a cemented or cementless implant was used. All operations were carried out by the senior author (Y-HK). No patient wore elastic stockings either before, during or after the operation. Two suction drains were used and were removed after 48 hours.

After operation, the limb was immobilised in a splint and elevated on two pillows. Quadriceps exercises were initiated on the first postoperative day when the splint and dressings were removed. Mobilisation started on the second postoperative day, as did knee movements using a continuous passive movement machine. No patient received prophylactic agents for DVT.

Coagulation assays (platelet count, prothrombin time, partial thromboplastin time, fibrinogen, antithrombin III and factor VIII), a full blood count, blood typing and serum chemical profile tests were carried out for all patients on three separate occasions: on the day before operation, on the second or third postoperative day and on the sixth or seventh postoperative day. Bilateral simultaneous or unilateral venograms were done on the sixth or seventh postoperative day. The criterion for diagnosing a DVT was a filling defect in a deep vein or defects surrounded by a narrow rim of contrast material. Patients with thrombi did not receive anticoagulation therapy, and they underwent further bilateral simultaneous or unilateral venograms at six months after operation in order to document the natural history of DVT.

Variations in the anatomy of the superficial femoral and popliteal veins were studied and the number of valves in the deep veins from the popliteal fossa to the level of the ischial spine were recorded. The incidence of DVT was correlated with these two factors.

All patients had ECG, chest radiography and serial determinations of blood gases and serum enzymes. All had perfusion lung scans before operation using a standardised technique. The preoperative examination was compared with that undertaken seven or eight days after operation in order to detect fresh pulmonary embolism. Ventilation lung scanning and pulmonary angiography were carried out if the perfusion lung scan was positive; if it was negative, no further studies were undertaken.

The blood loss at operation was assessed by weighing the swabs, calculating the amount of contained blood and adding this to the amount obtained from wound suction. The total volume obtained by suction drainage was taken as the postoperative blood loss. The amounts of blood and blood products or blood substitutes which were transfused intra- and postoperatively were recorded.

Statistical analysis was carried out using the chi-squared, Student's $t$ - and the Mann-Whitney U tests.

\section{Results}

After operation, of the 232 venograms in the 116 patients with a bilateral TKR, $97(41.8 \%)$ were positive for DVT compared with $46(41.4 \%)$ in the 111 patients with a unilateral TKR. This difference was not statistically significant $(\mathrm{p}=1.0,95 \%$ confidence interval (CI) -0.108 to $0.115)$. In the bilateral group, the venogram was positive for DVT in one limb in $39(16.8 \%)$ and in both in 29 patients $(25 \%)$.

The locations of the thrombi in both groups are shown in Table I. In the bilateral group most $(76,78.4 \%)$ were in the calf veins and in $21(21.6 \%)$ they extended proximally into the popliteal and/or femoral vein. In the unilateral group, most $(32,65.2 \%)$ were also in the calf and extended proximally into the popliteal and/or femoral vein in 14 (34.8\%).

Of the 116 venograms in the knees with a cemented replacement 45 (38.8\%) were positive for DVT compared with $52(44.8 \%)$ in the knees with a cementless replace-

Table I. The locations of thrombi after bilateral (116 patients) and unilateral (111 patients) TKR

\begin{tabular}{|c|c|c|c|c|}
\hline \multirow[b]{2}{*}{ Location } & \multicolumn{2}{|l|}{ Bilateral } & \multicolumn{2}{|l|}{ Unilateral } \\
\hline & Number of knees & $\%$ & Number of knees & $\%$ \\
\hline Calf veins & 76 & 78.4 & 32 & 65.2 \\
\hline Popliteal and calf veins & 15 & 15.6 & 4 & 8.7 \\
\hline Popliteal vein & 2 & 2.0 & 6 & 13.0 \\
\hline Femoral vein & 2 & 2.0 & 3 & 6.5 \\
\hline Femoral and calf vein & - & - & 1 & 2.2 \\
\hline Femoral, popliteal and calf veins & 2 & 2.0 & - & - \\
\hline Total & 97 & 100.0 & 46 & 100.0 \\
\hline
\end{tabular}


Table II. The locations of thrombi after 227 cemented and 116 cementless TKRs

\begin{tabular}{|c|c|c|c|c|}
\hline \multirow[b]{2}{*}{ Locations } & \multicolumn{2}{|l|}{ Cemented } & \multicolumn{2}{|l|}{ Cementless } \\
\hline & Number of knees & $\%$ & Number of knees & $\%$ \\
\hline Calf veins & 36 & 80.0 & 40 & 76.9 \\
\hline Popliteal and calf veins & 7 & 15.6 & 8 & 15.4 \\
\hline Popliteal vein & 1 & 2.2 & 1 & 1.9 \\
\hline Femoral vein & 1 & 2.2 & 1 & 1.9 \\
\hline Femoral, popliteal and calf veins & - & - & 2 & 3.9 \\
\hline Total & 45 & 100.0 & 52 & 100.0 \\
\hline
\end{tabular}

Table III. The relationship between venous anatomy and the number of knees (\%) with DVT in 227 patients (343 knees) undergoing TKR

\begin{tabular}{|c|c|c|c|}
\hline \multirow[b]{2}{*}{ Vein anatomy } & \multicolumn{3}{|l|}{ DVT } \\
\hline & Positive & Negative & Total \\
\hline Single superficial femoral vein & $65(18.9)$ & $94(27.4)$ & $159(46.3)$ \\
\hline Accessory femoral vein & $28(8.2)$ & $53(15.5)$ & $81(23.7)$ \\
\hline $\begin{array}{l}\text { Duplication of superficial } \\
\text { femoral and popliteal veins }\end{array}$ & $27(7.9)$ & $21(6.1)$ & $48(14.0)$ \\
\hline Duplication of popliteal vein & $18(5.2)$ & $23(6.7)$ & $41(11.9)$ \\
\hline $\begin{array}{l}\text { Duplication of popliteal and } \\
\text { multiple accessory superficial } \\
\text { femoral veins }\end{array}$ & $2(0.6)$ & $4(1.2)$ & $6(1.8)$ \\
\hline Multiple accessory popliteal vein & $2(0.6)$ & $3(0.9)$ & $5(1.5)$ \\
\hline $\begin{array}{l}\text { Multiple accessory superficial } \\
\text { femoral and multiple } \\
\text { popliteal veins }\end{array}$ & $1(0.3)$ & $2(0.6)$ & $3(0.9)$ \\
\hline Total & $143(41.7)$ & $200(58.3)$ & $343(100.0)$ \\
\hline
\end{tabular}

ment. This difference was not statistically significant ( $\mathrm{p}=0.675$, CI -0.187 to 0.066$)$. In both groups, most thrombi $(80 \%$ in the cemented and $76.9 \%$ in the cementless group) were in the calf veins. In nine limbs (20\%) with a cemented replacement and $12(23.1 \%)$ with a cementless replacement they extended proximally into the popliteal and/or femoral vein (Table II).

Using the Bonferroni method, ${ }^{22}$ the alpha level of each individual test was adjusted downwards to ensure that the overall risk for a number of tests remained 0.05 . In our study, the alpha level should be less than 0.0027 after 19 outcome measures to have a statistical significance. There was thus no relationship between DVT and the following factors in patients with and without thrombi, respectively: age (66.7 and 63.8 years), number of venous valves, duration of operation (151.7 and 152.6 minutes), amount of blood loss (approximately same in both groups), platelet count $(287144 / \mathrm{ml}$ and $265565 / \mathrm{ml})$, partial thromboplastin time (26.2 and 28.6 seconds), cholesterol level (237.2 and $226.1 \mathrm{mg} / \mathrm{ml})$, triglyceride level $(236.3$ and $177 \mathrm{mg} / \mathrm{ml})$, weight of patients $(64.3$ and $59.8 \mathrm{~kg}$ ), preoperative haematocrit levels, preoperative levels of total protein and calcium, the use of cement, and the presence of hypertension. There was also no relationship between DVT and gender (37.5\% of men and $41.7 \%$ of women), diagnosis (39.9\% of osteoarthritic patients and $35 \%$ of rheumatoid patients had thrombi), and venous anatomical variations (Table III).

The mean size of DVT was $10.1 \mathrm{~cm}$ (3 to 25$)$ in the bilateral and $11 \mathrm{~cm}$ (3.5 to 20) in the unilateral group. This difference was not statistically significant $(p=0.475)$. In the cemented group the mean size was $10.2 \mathrm{~cm}$ (3.5 to 20) and in the cementless group $10 \mathrm{~cm}$ (3 to 25). This difference also was not statistically significant $(\mathrm{p}=0.565)$. Table IV gives the size of the thrombi in different locations.

Venograms were repeated at six months after operation in all 143 limbs which had thrombi. All had completely resolved regardless of their location and size. No pulmonary embolism occurred in our series as shown by the negative perfusion lung scans and the absence of symptoms. Two patients died, one at 12 months and one at 14 months after operation, from causes which were unrelated to the operation. One patient had skin necrosis as a local complication of the venography caused by a leak of contrast medium and one had an allergic reaction to contrast medium.

\section{Discussion}

Our study shows a lower incidence of DVT after TKR in patients without thromboprophylaxis than in other studies reporting the use of some form of thromboprophylaxis. ${ }^{12,14,23,24}$ In these studies, the incidence of DVT was even higher in those patients who were given no

Table IV. Mean (cm; range) size of the DVT which occurred in 227 patients (343 knees) undergoing TKR

\begin{tabular}{lr}
\hline Location & \multicolumn{1}{c}{ Size } \\
\hline Calf vein & 9.7 ( 3 to 25$)$ \\
Popliteal and calf veins & $14.0(8$ to 20$)$ \\
Popliteal vein & 4.5 (5 to 15$)$ \\
Femoral vein & 3.4 (2 to 5) \\
\hline
\end{tabular}

THE JOURNAL OF BONE AND JOINT SURGERY 
prophylactic treatment. Our data, however, support those of others ${ }^{8,9}$ who have reported an incidence of $25 \%$ and $32 \%$, respectively, of DVT after cemented or cementless TKR in patients who had not received any thromboprophylaxis.

We could not confirm the widely accepted association between DVT and the following factors: advanced age, underlying disease, one-stage bilateral replacement, venous anatomical variation, the number of venous valves, coagulation assay data, blood type, hypertension, choice of cemented or cementless replacement, the complexity or duration of the operation, the operative blood loss, or transfused blood.

Although the subgroup of patients aged less than 40 years is too small to allow a proper statistical analysis to be performed, contrary to other reports, $7,13,16$ our study supports the view that advanced age does not constitute a risk factor. ${ }^{1,8,9,12,14}$

In our study, the predominant diagnosis was osteoarthritis, but with a low incidence of DVT. Although the subgroup of patients with rheumatoid arthritis is too small to allow a proper statistical analysis, our findings indicate that there is no specific correlation between the types of arthritis and the incidence of DVT. ${ }^{1,8,9,14,25}$ Contrary to the reports by Stulberg et al, ${ }^{14}$ our study shows that the incidence of DVT has no correlation with either one-stage bilateral or unilateral replacement. This finding agrees with that of Morrey et al. ${ }^{26}$ Also, contrary to the findings of Liu et al, ${ }^{27}$ we found no significant difference in the incidence of thrombosis between patients with anatomical venous variations and those without, or between patients with more than five valves and those with fewer. Our findings confirm those of Kim and Suh, ${ }^{28}$ and lead us to believe that there is no correlation between venous stasis and thrombosis.

Francis et $\mathrm{al}^{25}$ and Stulberg et al ${ }^{14}$ suggested that there was a possible correlation between antithrombin-III activity and the occurrence of DVT after a cemented total knee replacement. Others, ${ }^{8,9,27,28}$ however, found no such correlation and our findings support this conclusion. Likewise, we found no correlation between the use of acrylic cement and the development and the extent of thrombosis.

Obesity is generally believed to be associated with an increased incidence of DVT, ${ }^{7-9,24,29}$ but our study did not support this view.

Our findings did not confirm the view that hyperlipidaemia is not only associated with accelerated blood clotting, but also with increased blood viscosity and adhesiveness and aggregation of red blood cells. ${ }^{30}$

Most authors agree that patients with proximal thrombi are at the greatest risk of suffering symptomatic pulmonary embolism, ${ }^{1920,31,32}$ but the clinical significance of calf thrombi is disputed with some authors suggesting that asymptomatic calf thrombi pose little or no increased risk $^{8,9,20,24,25}$ and others reporting an increased risk. $^{3,10,13,19,33}$

In order to develop an effective protocol for the treatment of thromboembolic disease, the natural history of calf and proximal thrombi must be defined. Kakkar et $\mathrm{al}^{19}$ used venography and serial fibrinogen imaging to evaluate the progress of calf thrombi in a group of postoperative patients. They found that $23 \%$ of calf thrombi propagated to the proximal veins. Doouss ${ }^{33}$ did a similar evaluation and found an incidence of proximal propagation of 5.6\%. Maynard et $\mathrm{al}^{10}$ carried out serial venography on patients who had undergone TKR and found that $12 \%$ of calf thrombi which were identified within one day of surgery propagated to the proximal veins by the fifth postoperative day. Lotke et $\mathrm{al}^{32}$ reported that the incidence of asymptomatic pulmonary embolism was three times higher for patients with DVT than for those with negative venograms. Haas et $\mathrm{al}^{3}$ indicated that patients with calf thrombi have a significantly increased incidence of both asymptomatic and symptomatic pulmonary emboli compared with those without thrombi.

Our study indicates that patients with calf thrombi have no increased incidence of either asymptomatic or symptomatic pulmonary emboli compared with those without thrombi. In contrast to previous studies, ${ }^{19,20,31,32}$ we found no evidence of either asymptomatic or symptomatic pulmonary embolism in patients with proximal thrombi.

In addition to the location, the size of the thrombus may also be important. Some authors have shown that thrombi greater than $5 \mathrm{~mm}$ are more likely to propagate and embolise, ${ }^{19,32}$ while others ${ }^{20,24}$ have suggested that deep venous thrombi in the calf, of whatever size, are unlikely to produce symptomatic emboli and that therefore these patients do not require anticoagulation. Our findings support the latter. It has been speculated that thrombi in the calf are attached relatively securely and resolve rapidly and spontaneously. ${ }^{19}$ In our study all calf thrombi resolved spontaneously as shown by further venography six months after operation. If they do embolise, they are too small to produce symptoms and only a few are detected by ventilation-perfusion lung scanning. ${ }^{20}$ We found that thrombi often develop in the thigh after TKR $(21.6 \%$ in the bilateral and $34.8 \%$ in the unilateral group). In our study thrombi in the popliteal and femoral veins also resolved spontaneously.

Although the current prevailing opinion is that patients with thrombosis in the proximal veins should be treated by anticoagulation, our study has shown that all thrombi regardless of their location and size resolved without causing pulmonary embolism.

No benefits in any form have been received or will be received from a commercial party related directly or indirectly to the subject of this article.

\section{References}

1. Cohen SH, Ehrlich GE, Kauffman MS, Cope C. Thrombophlebitis following knee surgery. J Bone Joint Surg [Am] 1973;55-A:106-12.

2. Francis CW, Marder VJ, Evarts CM, Yaukoolbodi S. Two-step warfarin therapy: prevention of postoperative venous thrombosis without excessive bleeding. JAMA 1983;249:374-8. 
3. Haas SB, Insall JN, Scuderi GR, Windsor RE, Ghelman B. Pneumatic sequential-compression boots compared with aspirin prophylaxis of deep-vein thrombosis after total knee arthroplasty. J Bone Joint Surg [Am] 1990;72-A:27-31.

4. Hull R, Delmore T, Carter C, et al. Adjusted subcutaneous heparin versus warfarin sodium in the long-term treatment of venous thrombosis. N Engl J Med 1982;306:189-94.

5. Hull R, Delmore TJ, Genton E, et al. Warfarin sodium versus lowdose heparin in the long-term treatment of venous thrombosis. $N$ Engl J Med 1979;301:855-8.

6. Hull R, Delmore TJ, Hirsh J, et al. Effectiveness of intermittent pulsatile elastic stockings for the prevention of calf and thigh vein thrombosis in patients undergoing elective knee surgery. Thromb Res 1979; 16:37-45.

7. Hull RD, Raskob GE. Current concepts review. Prophylaxis of venous thromboembolic disease following hip and knee surgery. $J$ Bone Joint Surg [Am] 1986;68-A:146-50.

8. Kim Y-H. The incidence of deep vein thrombosis after cementless and cemented knee replacements. J Bone Joint Surg [Br] 1990;72-B:77983.

9. Kim Y-H, Kim VEM. Factors leading to low incidence of deep vein thrombosis after cementless and cemented total knee arthroplasty. Clin Orthop 1991;273:119-24.

10. Maynard MJ, Sculco TP, Ghelman B. Progression and regression of deep vein thrombosis after total knee arthroplasty. Clin Orthop 1991;273:125-30.

11. McKenna R, Galante J, Bachmann F. Prevention of venous thromboembolism after total knee replacement by high-dose aspirin or intermittent calf and thigh compression. $\mathrm{Br}$ Med $J$ 1980;280:514-7.

12. McKenna R, Bachmann F, Kaushal SP, Galante JO. Thromboembolic disease in patients undergoing total knee replacement. J Bone Joint Surg [Am] 1976;58-A:928-32.

13. Stringer MD, Steadman CA, Hedges AR, et al. Deep vein thrombosis after elective knee surgery: an incidence study in 312 patients. $J$ Bone Joint Surg [Br] 1989;71-B:492-7.

14. Stulberg BN, Insall JN, Williams GW, Ghelman B. Deep-vein thrombosis following total knee replacement: an analysis of six hundred and thirty-eight arthroplasties. J Bone Joint Surg [Am] 1984;66-A:194-201.

15. Lowe LW. Venous thrombosis and embolism. J Bone Joint Surg [Br] 1981;63-B:155-67.

16. Salzman EW, Harris WH. Prevention of venous thromboembolism in orthopaedic patients. J Bone Joint Surg [Am] 1976;58-A:90313.
17. Takats G, Jesser JH. Pulmonary embolism: suggestions for its diagnosis, prevention and management. $J$ Am Med Assn 1940;114:1415-21.

18. Hanel KC, Abbott WM, Reidy NC, et al. The role of two noninvasive tests in deep venous thrombosis. Ann Surg 1981;194:725-30.

19. Kakkar VV, Howe CT, Flanc C, Clarke MB. Natural history of postoperative deep-vein thrombosis. Lancet 1969;2:230-2.

20. Moser KM, Le Moine JR. Is embolic risk conditioned by location of deep venous thrombosis? Ann Intern Med 1981;94:439-44.

21. Stevens PM, Robin ED, Jackson D. Spurious pulmonary embolism: a nondisease. Heart and Lung 1979;8:141-7.

22. Rosner B. Fundamentals of biostatistics. Fifth ed. Pacific Grove, CA: Duxbury, 2000:527-30.

23. Lotke PA, Ecker ML, Alavi A, Berkowitz H. Indications for the treatment of deep venous thrombosis following total knee replacement. J Bone Joint Surg [Am] 1984;66-A:202-8.

24. Lotke PA, Steinberg ME, Ecker ML. Significance of deep venous thrombosis in the lower extremity after total joint arthroplasty. Clin Orthop 1994;299:25-30.

25. Francis CW, Pellegrini VD, Stulberg BN, et al. Prevention of venous thrombosis after total knee arthroplasty: comparison of antithrombin III and low-dose heparin with dextran. J Bone Joint Surg [Am] 1990;72-A:976-82.

26. Morrey BF, Adams RA, Ilstrup DM, Bryan RS. Complications and mortality associated with bilateral or unilateral total knee arthroplasty. J Bone Joint Surg [Am] 1987;69-A:484-8.

27. Liu GC, Ferris EJ, Reifsteck JR, et al. Effect of anatomic variations on deep venous thrombosis of the lower extremity. Am J Roentgenol 1986;146:845-8.

28. Kim Y-H, Suh J-S. Low incidence of deep-vein thrombosis after cementless total hip replacement. J Bone Joint Surg [Am] 1988;70-A:878-82.

29. Atik M, Harkess JW, Wichman H. Prevention of fatal pulmonary embolism. Surg Gynecol Obstet 1970;130:403-13.

30. Nicolaides AN, Irving D. Clinical factors and the risk of deep vein thrombosis. In: Nicolaides AN, ed. Thromboembolism: aetiology, advances in prevention and management. Baltimore: University Park Press, 1975:193-204.

31. Giachino A. Relationship between deep-vein thrombosis in the calf and fatal pulmonary embolism. Can J Surg 1988;31:129-30.

32. Lotke PA, Wong RY, Ecker ML. Asymptomatic pulmonary embolism after total knee replacement. Orthop Trans 1986;10:490.

33. Doouss TW. The clinical significance of venous thrombosis of the calf. Br J Surg 1976;63:377-8. 